\title{
On the retirement of Professor Rod Little
}

\section{B A Foëx, P M Dark, D W Yates}

\section{A key player in academic emergency medicine}

W hile 2002 saw the arrival of the Commonwealth Games in Manchester it also marked the departure of Professor Rod Little, who retired in April and moved to the Isle of Mull.

Dr Rod Little, as he then was, came to Manchester in 1977 when the MRC Toxicology Unit, headed by Professor H B Stoner, moved from Carshalton and became the MRC Trauma Unit. Rod became its acting director when Berry Stoner retired in 1984. A year later, in collaboration with the University of Manchester, the unit became the North Western Injury Research Centre, with Rod as its director.

Rod started his scientific career with a combined degree in zoology and physiology. His $\mathrm{PhD}$ on the physiology of injury in the newborn was supervised by Berry Stoner, in the Faculty of Medicine at the University of London. He continued his training in Sweden, first with a fellowship to the University of Gothenburg (1972-3), and then with a visiting professorship to the University of Uppsala (1978). During this time he met Professors David Lewis and Ulf Haglund, with whom he would later found the European Shock Society.

During his time in Manchester Rod Little helped develop numerous models to study the haemodynamic and metabolic responses to haemorrhage and injury, the neural mechanisms controlling these responses, and their immunological consequences. As a result he published more than 350 papers, reviews, and chapters on the pathophysiology of haemorrhage and injury. Over the years he supervised more than $20 \mathrm{MD}$ and $\mathrm{PhD}$ students, many of whom won international prizes.
Rod played a key part in developing the academic base of emergency medicine in this country. He was part of a small group that set up the Emergency Medicine Research Society in 1984. The society organised annual meetings to stimulate interest in the science of our practice. After the inauguration of the Faculty of Accident and Emergency Medicine in November 1993 these became the Faculty's Scientific Meetings and Rod became the first chairman of the new Faculty's Research Committee. The Faculty recognised Rod's contribution first by awarding him its Fellowship, by distinction, in 1994, and then by electing him Emeritus Professor, in November 2001.

Rod was closely associated with the Emergency Medicine Journal, and its predecessors the Journal of Accident and Emergency Medicine, and Archives in Emergency Medicine, having been a member of the

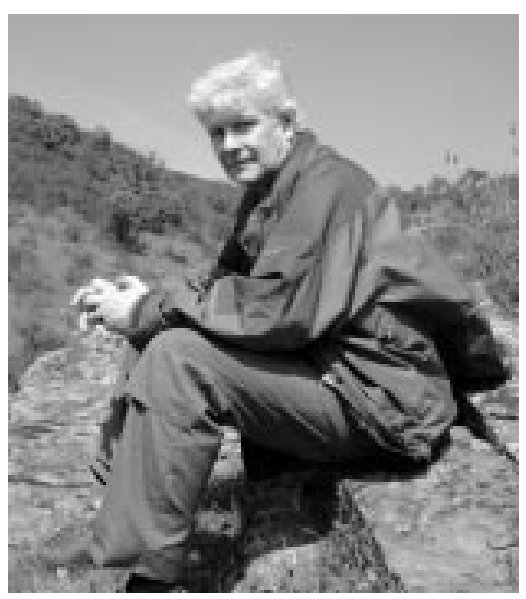

Figure 1 Professor Rod Little in Spain. editorial board of all three. He encouraged high standards and was instrumental in improving the quality of published material. This he also did in his role as European Editor of the journals Circulatory Shock, and then Shock.

Rod was one of the founders of the European Shock Society and served as its President from 1994 to 1996. He was closely involved in the scientific development of the Intensive Care Society, serving as a member of its scientific subcommittee from 1989, and as its Chairman from 1991 to 1999.

As a lecturer Rod has always been in demand and he has delivered numerous eponymous lectures, including the 1999 David Williams Lecture. He remains on the Court of Examiners for the Part 1 Memberships of the Royal College of Surgeons of England and of the Royal College of Surgeons of Glasgow. Until very recently he has been on the Research Board of the Royal College of Surgeons of Edinburgh. Rod continues to advise his former students and colleagues, but increasingly his scientific talents are being diverted to his lifelong interest in ornithology.

His most important contribution to the specialty has been that he, almost single handedly, trained a cohort of emergency physicians in the discipline of scientific inquiry. By his example and encouragement he allowed, those of us who had the good fortune to work with him, the opportunity to think critically and conduct carefully planned studies. Working with Rod was an education and a privilege. More than that it was great fun. For that we thank him and wish him, and his wife Gill, a very happy retirement, but hope he won't be too far from the telephone.

Emerg Med J 2003;20:2

Authors' affiliations

B A Foëx, Emergency Department,

Wythenshawe Hospital, Manchester, UK P M Dark, Emergency Department, Manchester Royal Infirmary, Manchester, UK D W Yates, Hope Hospital, Salford, UK

Correspondence to: Mr B A Foëx, 21 Sunnybrow Road, Middleton, Manchester M24 4AD, UK; bfoex@zen.co.uk 